\title{
ALGUNOS ASPECTOS SOBRE LA CONDICION DE POBREZA EN LA SAGRADA ESCRITURA
}

\section{Some Aspects of the Condition of Poverty in the Holy Scripture}

Alfredo Jerí Tafúr*

\begin{abstract}
RESUMEN
El presente artículo es una reflexión académica de un tema que es vinculante a la salvación y que tiene que ver estrictamente con la praxis cristiana. Escribir sobre algunos aspectos de la condición de pobreza en la Sagrada Escritura es hacer mención de un modo de proceder de parte de aquel que cree, además de una clara opción hecha de parte de Dios por los más vulnerables. La reflexión teológica nos llevará a concluir que la pobreza no es querida por Dios y que el pobre y su condición de pobreza serán siempre una tarea solidaria para el creyente, y una lucha interminable de nuestros pueblos por la justicia social.
\end{abstract}

\section{Palabras clave}

Pobre, pobreza, dignidad, liberación, salvación, redención.

\begin{abstract}
This paper is an academic reflection of a subjet that is related of the salvation and that has to do strictly with Christian praxis. To write about some aspects of the condition of poverty in Sacred Scripture is to mention a way of proceeding on the part of the one who believes, as well as a clear option made by God for the most vulnerable. The theological reflection will lead us to conclude that poverty is not wanted by God and that the poor and their condition of poverty will always be a solidary task for the believer, and an endless struggle of our people for social justice.
\end{abstract}

\section{Keywords}

Poor, poverty, dignity, liberation, salvation, redemption.

* Docente de la Universidad Femenina del Sagrado Corazón: alfredojerit@unife.edu.pe 


\section{INTRODUCCIÓN}

El pobre, su pobreza y la realidad que lo hace estar en esas condiciones inhumanas e indignas, es el tema que abordaré en este trabajo, iluminado por las Sagradas Escrituras. La reflexión y práctica que se deja entrever en la Biblia sobre el pobre y su realidad de pobreza ha sido, y es, para la Iglesia y para la teología un tema siempre vigente. Estar a favor del pobre, en términos modernos, pero también en términos antiguos, y sobre todo bíblicos, es hacer clara referencia al "indigente, al débil, al encorvado, al miserable, y a todos los que representan una condición humana degradada" (Gutiérrez, 2004, p. 93). Solo basta confrontar los textos bíblicos siguientes para evidenciar y concluir que los pobres de ayer son los mismos de hoy (Am. 2,6; 4,6; 5, 12; 8,4; $8,6 ; 5,11)$.

Integraré de manera sucinta a la vertiente bíblica-teológica, la dimensión social irrenunciable del mismo texto sagrado, ya que es importante tenerla como punto de apoyo y reflexión más acertada, pero no exclusiva, para el término pobre y la condición de pobreza que le acompaña. Se tendrá así, por un lado, la Sagrada Escritura, y por otro, el mismo contexto histórico en que se gesta la interpretación del sujeto y su condición materia de la presentación. En ambas realidades, la bíblica-teológica y la sociológica, entienden que la pobreza es una situación incomprendida, es por ello que en el desarrollo de muchos textos bíblicos se ponen de manifiesto el llamado al compromiso social a favor de los más frágiles y de aquellos que están en situaciones de precariedad, todo esto con el fin de poder erradicar la condición pobreza y la injusticia que la genera (Cf. Dt. 10,18; 24,19; Zac. 7,8; Jer. 22,3; Jb. 29, 11 ).
Describir esas duras situaciones de miseria y de pobreza, a decir verdad, provocadas por el mismo hombre, nos lleva a expresar lo que Job dice acertadamente:

Se llevan el asno de los huérfanos, toman en prenda el buey de la viuda, los mendigos tienen que retirarse del camino, a una se ocultan los pobres del país [...]. Desnudos andan, sin vestido; sin cobertor contra el frío. Calados por el turbión de las montañas, faltos de abrigo, se pegan a la roca. Se le roba al huérfano su campo, se toma en prenda la túnica del pobre (Job. 24,2ss).

Hacer referencia al "pobre" en la Biblia, y más estrictamente de su condición de pobreza en la que vive, lleva a hacer mención de una persona, y seguidamente de situaciones que le hacen vivir en ese estado de "pobreza". En tal sentido, hay que afirmar, haciendo eco a Tomás de Aquino en su escrito Contra Gentes III, 134: "Non enim paupertas secundum se bona est"1. Aquí surgen varias preguntas: ¿De qué pobreza hablamos? ¿Se puede diferenciar la pobreza material de la espiritual? ¿Qué referencias tenemos en las Sagradas Escrituras? Si se pueden diferenciar ambas pobrezas, entonces es válida esta otra pregunta: Cuando se habla del pobre, ¿se hace mención de aquel que lo es de espíritu o de aquel que lo es de la materia? Las respuestas se clarificarán en la medida que se avance con el texto.

En los escritos del Antiguo y Nuevo Testamento, se profundiza y reflexiona sobre la condición de pobreza y el sujeto que la encarna: el pobre. Más estrictamente, se vincula al pobre como un reflejo de la misma persona de Cristo, que es identificado en 2 Corintios 8,9 como

1 "La pobreza no es en sí misma algo bueno". 
Dios hecho pobre. Esta experiencia de abajamiento, de acción Kenótica, es comprensible solo por un acto de amor misericordioso. Así "el fundamento último de la preferencia por el pobre está en la bondad de Dios, y no en el análisis social o en la compasión humana, por relevantes que estas cosas puedan ser" (Gutiérrez, 1995, pp.16 17). Hablar del pobre y de su condición de pobreza, con la finalidad de cambiar su historia, dignificarlos e incluirlos, no siempre es una voluntad que vaya acompañada de buenas intenciones ya que en muchísimas ocasiones se les utiliza como medios para alcanzar fines particulares.

No es fácil poder definir con exactitud el término pobreza en el ámbito bíblico ya que aparece en la Sagrada Escritura de manera, por así decirlo, ambigua. En unos casos se refiere a la pobreza material y en otras a la pobreza espiritual como un ideal de la vida. En el primer caso se entiende como aquella situación con la que hay que luchar, porque condiciona la libertad del ser humano y toda su dignidad. Por ejemplo, en el ámbito social se entiende la pobreza como aquella realidad que tiene que ser transformada con mayores bienes económicos para, crear condiciones de vida más dignas, pero habrá que luchar por aquello que genera esas condiciones y que muchas veces son las causantes de una sociedad desigual. La pobreza, afirma Gustavo Gutiérrez, es:

Carencia de alimento y de techo, imposibilidad de atender debidamente a necesidades de salud y educación, explotación del trabajo, desempleo permanente, falta de respeto a la dignidad humana e injustas limitaciones a la libertad personal en el campo de la expresión, en lo político y en lo religioso, sufrimiento diario (citado por Illacuría y Sobrino, 1990, p.304).

De esta manera, la pobreza será todo aquello que es contrario a la voluntad de Dios, que afecta la integridad de la persona y que ya es condenado en la Sagrada Escritura. El teólogo Juan Pablo García Maestro, define al pobre como: "el sujeto que por su situación está condenado a una muerte temprana e injusta" (2013, p.246). Es cierto, en todas las sociedades encontramos pobres, y es el mismo Jesús quien deja saber que siempre tendremos pobres a nuestro lado (Cf. Mt. 26,16). Al respecto se debe tener en cuenta lo siguiente: primero, saber que siempre habrá pobres en nuestra sociedad, y segundo, que es lo más incomprensible, que haya indiferencia y se viva a espaldas de ellos. La cuestión, a mi parecer, no está en si habrá pobres o no, sino en la capacidad que tenemos de sentirnos hermanos y hacer que las necesidades del otro sean también las nuestras. Es decir, hacernos solidarios con el que sufre y, lo más importante, ayudar a emanciparse de su condición y buscar liberarlo-salvarlo integralmente de su pobreza.

\section{1.- LA POBREZA EN EL ANTIGUO TESTAMENTO}

La opción que hace Dios en el Antiguo Testamento, y que continúa en el Nuevo Testamento, será clave para entender el corazón de la propuesta liberadora y redentora de Jesús, quien hace a una opción por el débil, por el frágil, por el excluido, por el pobre, por el último. Ya en el Antiguo Testamento se relaciona al pobre como aquel que carece de medios para vivir, generando así la condición de pobreza. Se puede decir que "frente a la pobreza hay tres reacciones fundamentales: $1^{\text {a }}$ La pobreza es considerada como castigo (Prov. 
$3,10 ; 15,6) .2^{\text {a }}$ La pobreza es un mal social (Eclo. 13, 17-23; Lev 25,35-36; Dt 15, 1 9). $3^{\text {a }}$ La pobreza es el ideal de vida (Eclo. 31, 5-7)" (Fernández, 2015, p.999). Como se deja notar en los textos antes citados, no se puede abordar el tema de la pobreza desde un solo ángulo, por ello el acercamiento necesario a la sociología ha de ser una constante en la reflexión teológica.

La opción de Dios en el Antiguo Testamento es clara. Se inclina de manera especial por aquellos que viven en condiciones de pobreza, o lo que es más triste decir, empobrecidos. De esta manera se puede afirmar que nuestro Dios "es un Dios que toma partido por el pobre y que lo libera de la esclavitud y de la opresión" (Gutiérrez, 1980, 17). En ese sentido, su inserción en nuestro mundo y en la historia, no tiene por finalidad demostrar su poder sino hacer presente el Reino del amor y dejar claro que una vida de creencia en Dios no puede estar divorciada del compromiso con los pobres y de una denuncia constante de las condiciones en las que viven: "Padre de los huérfanos y tutor de las viudas es Dios en su santa morada; Dios da a los desvalidos el cobijo de una casa, abre a los cautivos la puerta de la dicha..." (Sal. 68,6-7).

Las citas que ponen de manifiesto una clara presencia del pobre en relación a la iniciativa divina son diversas (Sal 12, 6; Sal 71, 4- 12- 14; 1 Sam 2,1ss), esto con el objetivo de incorporarlo a una sociedad que los excluye, y de esta manera no perderlos de vista en el paso por esta vida. Es Dios quien está al servicio de la justicia y de los pobres (Sof. 2,3; 3,11-13) y su grandeza es manifestada en la defensa de los más vulnerables (Sal 146,7-9). También en los libros proféticos encontramos un claro aspecto del anuncio y denuncia a favor del pobre; se refleja que no se puede ser permisivo frente a la postura de aquellos que, siendo ricos, oprimen a los débiles con injusticias. También en el Antiguo Testamento se lee: "El Espíritu del Señor está sobre mí y me ha ungido y enviado a anunciar la Buena Nueva a los pobres, a vendar los corazones rotos, pregonar la libertad a los cautivos y el año de gracia del Señor" (Is. 61,1-2). En consonancia con lo escrito, el biblista español José Luis Sicre ${ }^{2}$ lo expresará de esta manera: "Uno de los aspectos más famosos e importantes del mensaje profético lo constituye su denuncia de los problemas sociales y su esfuerzo por una sociedad más justa" (1992, p.337). En ese sentido, va quedando más claro que Dios no está ni a favor, ni promueve la pobreza. Son los profetas quienes se encargaron de relacionar a ese sujeto concreto "pobre" y a su "condición de pobreza" con palabras fácilmente reconocibles y que además son sacadas de la propia experiencia social. Ellos "no dudaron en condenar el comercio fraudulento y la explotación (Os 12,8; Am 8,5; Miq 6, 10 11; Is 3, 14; Jer $5,27)$; la violencia de las clases dominantes (2 Re. 23,30-35; Am. 4, 1; Miq. 3, 1 -2; 6, 12; Jer. 22, 13-17); a los funcionarios abusivos (Am. 5,7; Jer. 5,28)".

En este apartado no solo encontramos denuncias de situaciones que atentan contra el pobre, sino que también encontramos medidas para solucionar este problema y poder de esta manera impedir que se instale en medio del pueblo. Así, encontramos en Levítico y Deuteronomio una serie de legislaciones que pretenden impedir o regular la acumulación de riqueza que lleva consigo

2 Profesor emérito de la Facultad de Teología de Granada, del Pontificio Instituto Bíblico de Roma y de la Facultad de Teología de San Miguel (Buenos Aires). Es autor de numerosos artículos y de diversas obras relacionadas con los estudios bíblicos. 
la explotación de los vulnerables. Un gesto de vital importancia será que no habrá que ir buscando las sobras del campo después de realizada la siega, porque esta será destinada para el forastero, el huérfano y la viuda (Dt. 24,19-21; Lev. 19,9-10). El diezmo trienal, por ejemplo, no será llevado al templo, sino que será para el forastero, el huérfano y la viuda (Dt 14,28 $29 ; 26,12)$, cuestiones más generales, pero de vital importancia es que cada siete años las tierras serán dejadas en descanso "para que coman los pobres de tu pueblo" (Ex. 22, 11; Lv. 25,2-7). También el séptimo año los esclavos recobraban su libertad (Ex. 21,6$)$ y se condonaban las deudas (Dt. 15,1-18).

En el acontecimiento heroico que hizo Moisés de sacar de la esclavitud y de la explotación de Egipto a su pueblo para llevarlo a una tierra donde encontrarían paz y dignidad, se da la alianza en la que ambas partes se muestran íntegramente de cara a la fidelidad de la promesa. Los israelitas ya no son un pueblo cualquiera, pobre y esclavo, ahora son el pueblo de Dios, su pueblo, así Israel vivió el pasmo de saberse elegido siendo el menor de los pueblos. Por ello se entenderá que oprimir al pobre será ir contra Dios mismo, porque ellos son su pertenencia, y lo que se haga a los demás revertirá también en el Señor. Se entiende los textos de los profetas como una denuncia a todas las injusticias que vive el pueblo para que así no se repita la historia de esclavitud de la cual fueron sacados para ser liberados.

"Para rechazar la pobreza, los profetas, herederos del ideal mosaico, se referirán al pasado, a los orígenes del pueblo; en ellos se buscarán la inspiración para la construcción actual de una sociedad justa. Aceptar la pobreza y la injusticia es recaer en la situación de servidumbre, anterior a la liberación de Egipto. Es retroceder" (Sicre, 1992, p.337).

Siguiendo la interpretación que hace el teólogo español Juan Pablo García Maestro sobre de los términos con los cuales aparecen relacionados los pobres en el Antiguo Testamento, se nota que todas las connotaciones están aún vigentes. Así encontramos ebyon (61 veces) para designar al mendigo, al que le falta algo y tiene una necesidad. Ese es el que espera solidaridad del otro, de su próximo, de su hermano. Otra palabra que también se refiere al pobre es dal (48 veces) que significa flaco, y que en contextos de carencia social toma mayor vigencia. Tenemos aní (80 veces) que alude al encorvado, que es lo mismo a decir, al que está bajo un peso, el humillado, el que trabaja sin descanso para ganarse unas monedas y ya ha perdido la esperanza. Todas estas palabras están vinculadas al ámbito civil o político, pero cuando se desea expresar pobre en sentido religioso se emplea Anaw (25 veces) (García Maestro, 2013, p.248).

Como se pone de manifiesto en las anotaciones, la mayoría de las connotaciones de la condición de pobreza, hacen referencia a la carencia material y dentro del ámbito social-no religioso. Este detalle es importante resaltarlo porque es la realidad del pobre, del huérfano y de la viuda- su situación social-, y la manera cómo entramos en relación con ellos, la que va a determinar nuestra pertenencia al pueblo elegido.

\section{2.- LA POBREZA EN EL NUEVO TESTAMENTO}

Con respecto al Nuevo Testamento, los siguientes textos son clave para entender la experiencia de abajamiento 
más extrema de parte de Dios, la kénosis: "Pues ya conocen la generosidad de nuestro Señor Jesucristo, el cual, siendo rico, se hizo pobre por ustedes para que su pobreza les hiciera ricos" (2 Cor. 8,9) y más precisamente: "Tened los mismos sentimientos de Cristo, el cual siendo de condición divina, no codició el ser igual a Dios, sino que se despojó de sí mismo tomando condición de esclavo" (Flp. 2,5). Él, compartiendo todo igual a nosotros, menos en el pecado, quiso salvarnos desde abajo, desde lo más carente de nuestra condición humana y por eso mismo el tema de la pobreza en el Nuevo Testamento cobrará vitalidad con la forma de entender la salvación, porque no será para Jesús el cumplimiento de las normas o preceptos lo que determine la pertenencia a Dios, sino el compromiso verdadero de estar al lado de aquellos a quienes nadie ama (Mt 25,35-45) y que son pequeños (Mt. 10, 42; Mt. 18,6.10.14; Mt 1,25).

Innegablemente, Jesús de Nazaret ha marcado un hito en el devenir de la humanidad; no es un personaje cualquiera, ha dividido la historia en un antes y un después, así fue que su vida y su prédica no han sido insignificantes hasta el punto de que, al día de hoy, su mensaje sigue cobrando valor e ilusión en la gente, sobre todo porque su compromiso fue con los más desprotegidos (Mt. 18,2 4; 19,13-14). Siguiendo a Jesús a través del Nuevo Testamento, se cae en la cuenta de que todas sus palabras van acompañadas de gestos y acciones, además, nada hay en él que no sea coherente. Por ejemplo, se compadece de la gente que no tiene que comer (Mt. 4,4; Mc. 6,32-44). Fue su manera de vivir, lo que le hizo un líder pacifico. No hay en él discursos vacíos ni virulentas quejas sobre la realidad social. Por el contrario, su comprensión de la realidad con ojos de objetividad, lo hace vivir como piensa y ser consecuente con su misión. El centro de todo su discurso es el Reino, pero queda claro que ese Reino anunciado tiene como destinatario principal al ser humano, su liberación, su redención y su salvación, y la reivindicación de su condición, especialmente la de aquellos que viven en condiciones de pobreza. Jesús no solo vivió liberando del mal y del pecado a la gente, sino que tuvo un compromiso con los más frágiles:
"Me ha enviado a anunciar a los pobres la Buena Nueva, a proclamar la liberación a los cautivos y la vista a los ciegos, para dar la libertad a los oprimidos y proclamar un año de gracias del Señor [...]. Esta Escritura que acaban de oír, se ha cumplido hoy" (Lc 4, 16,21; citando a Is $61,1-2)$.

El anuncio de liberación y redención que hizo Jesús llenó y sigue llenando de ilusión a propios y extraños, sobre todo llenó de esperanza a un pueblo sufriente y empobrecido, al resto de Israel. El cumplimiento de esa Buena Noticia será puesto de manifiesto en las curaciones que se hacen a los enfermos, porque esto permite alejarse del sufrimiento. En Lucas 7,21 se afirma que "el mismo Jesús curó muchas enfermedades, ataques y malos espíritus, y a muchos ciegos les devolvió la vista". Así, nuevamente, la noticia que alegra los corazones de los afligidos es que ese anuncio de la Buena Nueva a los pobres no es otra cosa que esperar que algún día dejarán su condición de pobreza y se emanciparán de esa condición que les quita dignidad. De la misma manera que se lee, primero como promesa y luego como cumplimiento, que los ciegos ven, que los sordos oyen y que los muertos recobran vida, así el anuncio a favor de los pobres es una alegría anticipada para poder gozar de una sociedad sin exclusiones. Así los 
pobres dejarán su pobreza y ya no serán víctimas de una sociedad indiferente.

Es fácil de comprobar a través de una lectura seria de los evangelios que Jesús se muestra siempre cercano a pecadores y con espíritu de apertura frente a los más frágiles y vulnerables (Mt. 11,19; Lc. 7, 34; Mc 2,19). La peculiaridad del mensaje de Jesús es que jamás deja de estar acompañado de las obras, es decir, vive lo que predica, hay coherencia en su mensaje y por ello se puede afirmar que su muerte fue consecuencia de su forma de vida (Mt. 27,52). El discurso de Jesús gira en la correcta relación del hombre con Dios, de Dios con el hombre y de los hombres con los mismos hombres. El mismo Jesús nos enseñó todo lo que aprendió de su Padre: la misericordia, el amor y el perdón; y al darnos a conocer esa vinculación íntima, nos hace amigos suyos, de esta manera no nos llama siervos sino amigos porque nos ha dado a conocer todo aquello que aprendió del Padre (Jn. 15,15). Innumerables textos ponen de manifiesto la nobleza del corazón de Jesús y su opción preferencial por aquellos que la sociedad de antaño y la actual excluyen. Tenemos por ejemplo al leproso al que Jesús dijo: "Quiero, queda limpio" (Mc. 14,36; Lc. 22,42). Le sigue el criado del centurión, el que, en un momento determinado, había quedado sano (Mt. 8,3ss). Seguidamente aparece la suegra de Pedro y otros que también fueron curados (Mt. 8, 14,22). Se encuentran también los endemoniados liberados (Mt. 8, 28-30), y el paralítico al que Jesús perdonó los pecados y curó la parálisis (Mt. 9, 1-7). No menos importante es la mujer enferma, la que tocó la orla del manto de Jesús y la hija de Jairo (Mt. 9, 18-26). Asimismo, encontramos a los ciegos a los que Jesús había abierto los ojos (Mt. 9, 27-31) y el hombre mudo (Mt. 9, 32-34). Todos estos textos son también ejemplos de pobreza, una pobreza que ha de ser entendida como exclusión de la comunidad.

Se encuentran innumerables citas que muestran la compasión de Jesús al ver a la gente pobre sufrir. Pero eso no es todo, además él exhorta que se tenga la misma intensidad de amor para con nuestros enemigos, y así de esta manera su amor se siga prolongando (Mt. 5, 43-44). Jesús no solo es amigo de los pobres, sino que es un pobre entre los pobres, su vida la vive en medio de su gente y por eso puede comprender sus necesidades. Poniendo su morada en medio de nosotros (Jn. $1,14)$ es capaz de entender las carencias de los ciudadanos de a pie, por ello sus mensajes no son ajenos al cotidiano vivir y tienen gran impacto en la gente, porque habla desde su propia condición de pobreza. Así es Jesús, el Mesías, va contra corriente ya que sabe que su misión liberadora, redentora y salvífica pasa por la dignificación de la persona para hacer presencia del Reino en medio del pueblo.

"El alivio al sufrimiento de unos cuantos pobres en el tiempo de Jesús es promesa firme de que la Buena Nueva del reinado de Dios es anunciada a todos los pobres de la historia. Anunció a través de palabras y gestos liberadores. Se proclama el Evangelio a los pobres por medio de acciones concretas; hacer ver, andar, oír, en una palabra, dar vida. Esto es lo que significa acordarse de los pobres [...]. No hay auténtica evangelización sin obras a favor del pobre" (García Maestro, 2013, p. 119).

Pero ¿cómo ve Jesús a los pobres de su tiempo?, ¿cómo se sensibiliza ante el sufrimiento ajeno?, ¿cómo logra compenetrarse en las injusticias hasta 
el punto de exponer su vida por estar a favor de los más frágiles? Para poder responder estas y otras preguntas que tienen que ver con el compromiso real de Jesús por los pobres es necesario hacer una lectura profunda y seria de las Sagradas Escrituras. Aquí sólo mencionaré algunas de ellas, con la finalidad de mostrar que las actitudes de Jesús son claves para entender "su filosofía" o, mejor dicho, su teología, o más precisamente, su práctica pastoral.

Por ejemplo, los textos de Marcos 12, 41-44 y de Lucas 21, 1-4 que hacen mención del óbolo de la viuda ponen de manifiesto una primera actitud: "Jesús se sentó frente al arca del tesoro y miraba cómo echaba la gente monedas en el arca del tesoro" (Mc. 12,41). Este bellísimo texto, como todos los de la Sagrada Escritura, puede ser abordado desde distintos ángulos, quizá el más profundo y por el cual me inclino, es aquel que valora la intención y el buen corazón de la pobre viuda que dio lo poco que tenía, aquello que le hacía falta para vivir (Mc. 12,44). No dudo que el Señor ve la intención del corazón, pero antes de eso, hay un gesto de parte de Jesús que no podemos perder de vista en este texto. Antes de ver la intención del corazón, Él se sitúa en el lugar perfecto y estratégico, espacio que le permitirá apreciar con mayor claridad lo que se viene desenvolviendo en torno al templo y específicamente al tesoro. Ya ubicado, o como dice el texto literalmente: "Jesús se sentó frente al arca del tesoro", es claro que la intención que tiene es ver la actitud de la gente que pasa, que va o que deposita su óbolo en aquel lugar.

Pienso, no se puede salir al encuentro de alguien sin antes haberlo visto, no se puede hablar de una situación real y concreta si antes no hemos sido testigos, no podemos hablar de los pobres y de su condición si antes no hay un compromiso con su realidad, con su circunstancia, con su mundo. Esa es la actitud y disposición de Jesús en todos los pasajes que ilustran su deseo por reivindicar la condición del pobre frente a algún tipo de injustica, o delante de alguien al que desea dar lecciones de misericordia. Él busca dejar claro que ha venido a salvar la integridad del ser humano (Jn. 10,10), "y porque supo ver, pudo decir que la limosna de la viuda valía mucho, mucho más que las otras; es decir, aquella que a un observador poco atento le pudo haber parecido una limosna más, es resaltada por el Señor" (Gutiérrez, 2004, p.288). Hay toda una pedagogía en el actuar de Jesús que más bellamente se deja notar cuando busca la inclusión de aquellos que son excluidos por su propia condición, pobres finalmente.

\section{3.- LA POBREZA MATERIAL EN LAS BIENAVENTURANZAS DE LUCAS}

Cuando Lucas expresa las bienaventuranzas (Cf. Lc. 6, 20-49) y pone al pobre en un lugar de privilegio, no pretende sacralizar la miseria, la injusticia y su condición de pobreza. Algunos se atreven a decir que la pobreza material, ausencia de bienes, será recompensada en el cielo, "los partidarios de esta interpretación conciben la felicidad eterna de los pobres como una compensación justa de los sufrimientos que padecieron en esta tierra" (Iraburu, 1964, p. 31). Tampoco se pretende resaltar una clase social o minusvalorar a los que tienen tal o cual situación económica. Lucas entiende que hay que resaltar la condición de pobreza para crear un espíritu solidario en el prójimo y, de esta manera, hacer que las desigualdades sean cada vez menores, pero de ninguna manera entiende que Jesús haya santificado alguna clase social o que los evangelios hayan canonizado algún estrato económico. 
Queda claro que la persona no se salva por la clase social a la que pertenece, sea pobre o rico, sin embargo, Lucas hace una mención especial en las bienaventuranzas a la pobreza material porque "el evangelista es de mayor sensibilidad a las realidades sociales" (García Maestro, 2013, p. 260) y por ello en su escrito llama al compromiso social. Así también deja notar en su escrito de los Hechos de los Apóstoles (Cf. Hch 2,42) donde el tema de la pobreza material y de la puesta en común de las propiedades es muy frecuente 3 . Que Lucas haga mención del pobre material en las bienaventuranzas, solo pone de manifiesto una condición social que se caracteriza por la carencia de bienes materiales, a causa de la cual, viven en condiciones de carencia, de miseria y de indigencia. Juan Pablo García Maestro les denomina: "grupo social marginado, con un matiz de opresión y de falta de libertad" (2013, p.262).

Hay una pedagogía en el escrito lucano, principalmente en las bienaventuranzas. "La estructura de su discurso tiene cuatro destinatarios: los pobres, los hambrientos, los tristes y los perseguidos por su causa" (Lagner, 2018, p.114). Afirma Lucas, que "los pobres son bienaventurados porque de ellos es el Reino de los cielos", esto no significa de ninguna manera, afirma el teólogo peruano Gutiérrez: "aceptar la pobreza, porque más tarde esa injusticia será compensada en el reino de Dios" (1974, p.365).

Si líneas arriba he mencionado que la pobreza es contraria a la voluntad de Dios, ¿cómo es posible que ahora se diga que son bienaventurados los pobres? ¿Cómo explicar esta aparente contradicción? El biblista François Bovon, en su libro "El
Evangelio según San Lucas", presenta una explicación del desarrollo del tema de la pobreza "material" puesta en los escritos de Lucas y Hechos, principalmente basados en la visión de pobres y ricos que el mismo Lucas tiene y, teniendo en cuenta a los destinatarios de sus escritos. Cuando habla del pobre está haciendo mención de aquella persona que carece de los bienes de este mundo, que viven en estado de miseria o, al menos, están en estado de indigencia (2010, pp. 416-428).

Un texto clásico, siguiendo al mismo Lucas y en relación con las bienaventuranzas, es Hechos 2, 42ss donde se escribe sobre la vida fraterna y comunitaria. El ideal de vida que propone Lucas es muy interesante resaltarlo, porque es sabido que no se vivía en plenitud lo expresado, sino que es un camino en que todos los miembros de la comunidad participan de su construcción. La biblista alemana Cordula Langner la denominará "sumario idealizado de la primera comunidad", espacio donde "todos los creyentes vivían unidos y tenían todo en común" (Hch. 2,44), "nadie llamaba suyo a sus bienes, sino que todo lo tenían en común" (Hch. 4,32), y todo esto lo hacían teniendo "un solo corazón y una sola alma" (Hch. 4,32). Aquí lo que se busca dejar claro es el compartir, la solidaridad, el tener la capacidad de desprendimiento y no tener nada que haga ser esclavos de los bienes materiales, de esta forma se podía lograr el ideal cristiano. "No había entre ellos ningún necesitado porque todos los que poseían campos o casas los vendían, traían el importe de la venta y lo ponían a los pies de los apóstoles, y se repartía a cada uno según sus necesidades" (Hch. 4,34).

3 Ignacio Ellacuría en esta misma línea afirma: "A Lucas se le ha llamado el evangelio social, por su preocupación tanto violenta por la desigualdad entre pobres y ricos. La designación es tanto más significativa cuanto que es también el evangelista de la misericordia y del perdón, el evangelista de la gracia". Cf. Las bienaventuranzas, carta fundacional de la Iglesia de los pobres. 139. 
Es claro que se busca una sociedad donde no haya pobres, el sentido de la comunidad, de compartir los bienes, será suprimir la condición de pobreza por amor al pobre. "Si se tienen los bienes en común, no es para hacerse pobres por amor de un ideal de pobreza, sino para que no haya pobres: el ideal perseguido es, una vez más, el de la caridad, el de un amor verdadero por los pobres" (García Maestro, 2013, p.277). Mejor aún, se busca suprimir la pobreza por amor al pobre, pero con espíritu solidario y de caridad, sin confundir los términos comunión y comunismo, porque lo que pretende Lucas es mostrarnos una comunidad solidaria y no igualitaria.

\section{4. - LA POBREZA ESPIRITUAL EN LAS BIENAVENTURANZAS DE MATEO}

El tema de la pobreza en el evangelio de Mateo es tratado desde una mirada espiritual. "Bienaventurados los pobres de espíritu porque de ellos es el reino de los cielos" (Mt. 5,3). Ha de entenderse aquí pobreza de espíritu como una "infancia espiritual", es decir, como una disposición de apertura a lo divino que reconoce constantemente su necesidad y su carencia como confirmación de un deseo de búsqueda natural. Se puede añadir y entenderlo, además, como la disposición humilde de apertura a Dios. Siendo más rigurosos, se puede decir que la primera bienaventuranza es "la madre y engendradora de las virtudes; pues quien despreciare los bienes del mundo conseguirá los eternos" (San Ambrosio, 1966, p.254). En Lucas no se menciona la palabra "pobres de espíritu", con lo cual se puede suponer que, al referirse al término pobre, lo está haciendo para marcar un territorio distinto al de Mateo y esto se puede demostrar porque todo el escrito lucano, me refiero al Evangelio y Hechos de los Apóstoles, tienen una fuerte carga social (Ellacuría, 1981, pp.56-69). Aquí ha de entenderse la alusión de pobreza espiritual a Mateo ya que él desarrolla esta cuestión, no así sucede con Lucas, quien se encarga de hacer mayor énfasis en la pobreza material.

Uno de los sentidos que más acogida ha tenido entre exégetas es el que se refiere a la pobreza espiritual como la actitud de disposición a lo trascendente, es decir no sentirse que ya se ha alcanzado todo y por ello no se necesita de nada. Ser pobre en el espíritu será reconocer que somos, por así decirlo, niños en etapa de desarrollo, sin querer sentirse adultos, o, mejor dicho, se trata de ser eternos infantes espirituales que reconocen que aún les falta mucho por recorrer y aprender. Con todo esto no se pretende la búsqueda de renuncia a los bienes materiales o ser indiferente a ellos, ya que son básicos y necesarios, sino se trata de una cuestión de mayor significación: hacer la voluntad del Padre, así seremos imitadores de Cristo.

Es cierto que las bienaventuranzas abren el capítulo que se podría llamar o reconocer como el sermón de la montaña, haciendo clara alusión sinóptica a las leyes dadas a Moisés en el monte Sinaí (Cf. Ex. 19ss; 20ss). Mientras que en el libro del Éxodo se presenta las grandes directrices éticas para el comportamiento del pueblo de Israel, en Mateo se buscan nuevas formas de compromiso para amar a los demás, y entenderla como una nueva ley: "Antes se dijo, ahora yo les digo" (Mt. 5,38). Se va dejando notar que el término "pobres de espíritu" está estrechamente vinculado al anuncio del reino en Mateo, es decir, discipulado, pobres y reino van de la mano. Pero aquí hay que añadir algo importante: la palabra justicia, porque en Mateo está también vinculada al reino: "busquen primero el Reino y su justicia" 
(Mt 6, 33). Asimismo, podemos encontrar 7 veces el término justicia en Mateo, 1 en Lucas y 0 en Marcos.

La expresión de Mateo: "bienaventurados los pobres de espíritu, porque de ellos es el Reino de los Cielos" (Mt 5,3) invita a disfrutar desde ahora ese reino de los cielos, que no es una promesa, es una realidad. Lo que con Sofonías en el siglo VII a.C se esperaba, se hará realidad en la obra del Mesías y los pobres: "Yo dejaré en medio de ti un pueblo humilde y pobre, y en el nombre de Yahvé se cobijará el resto de Israel" (Sof. 3,12 13); así el término pobreza adquiere un sentido espiritual y será presentada en adelante como un ideal: "Buscar a Yavéh, todos ustedes, pobres de la tierra, que cumplen sus normas; buscar la justicia, buscar la pobreza" (Sof. 2,3).

\section{5.- BREVE MIRADA PASTORAL: LOS POBRES EVANGELIZAN}

Decir que los pobres evangelizan es afirmar que ellos son portadores de una verdad que se les ha entregado como misión y que tiene como punto de partida el acontecimiento de la Resurrección que se confirmó más plenamente en Pentecostés. (Cf. Mt. 1,7; Hch. 2,1-11). Decir que la Iglesia es de los pobres, y que, por consiguiente, ellos también evangelizan, es una afirmación muy antigua y San Pablo la plasmó de esta manera:

Hermanos, fíjense a quienes los llamó Dios: no a muchos intelectuales, ni a muchos poderosos; ni a muchos de buena familia; todo lo contrario; lo necio del mundo se lo escogió Dios para humillar a los sabios y lo débil del mundo se lo escogió Dios para humillar a lo fuerte (1 Cor. 1,26 ss).
Los ciudadanos de Corinto tienen a sus propios evangelizadores dentro de su comunidad. No son los fuertes, los sabios, ni los ricos, sino los débiles, los desprotegidos, los que "no existen", los que son empobrecidos; así queda sentada la afirmación de Iglesia de los pobres. Si para Lucas lo central de su mensaje es el anuncio de la Buena Nueva a los pobres, esto no se puede concretar sin la liberación de los cautivos, dar vista a los ciegos, libertad a los oprimidos. Esa noticia traída por Jesús está íntimamente relacionada con la liberación. Todo el actuar de Jesús, de su anuncio del Reino y de sus milagros, están a favor de los pobres y oprimidos. Así ellos sienten suyo el cumplimiento de la promesa de salvación y por ende son portadores también de esa Buena Noticia que se ha concretado en sus propias vidas.

En el Antiguo Testamento Dios hace una opción, en el Nuevo Testamento Jesús hace una opción, en los inicios del cristianismo las comunidades hacen una clara opción, la Iglesia, en todo su devenir histórico, también hace una opción; la Iglesia latinoamericana hace eco de esta opción en Medellín afirmando la intención de presentar "el rostro de una Iglesia auténticamente pobre [...]. Y audazmente comprometida con la liberación de todo el hombre y de todos los hombres" (Medellín, 15). El talante de este deseo es netamente cristológico y surgirá, en adelante, variadas relaciones que identifiquen a los pobres con Cristo y también como continuadores de su misión. Por ejemplo, en uno de los documentos del Vaticano II, Lumen Gentium, se afirma que la Iglesia "reconoce en los pobres y en los que sufren la imagen de su fundador pobre y paciente [...]. Y procura servir en ellos a Cristo" (LG. 8). Asimismo, Puebla afirmó bellamente que "los rasgos de Cristo 
están presentes en los rostros muy concretos de los pobres" (Puebla, 31 -39).

El pobre tiene un lugar de pertenencia dentro de la Iglesia, y la Iglesia es y quiere ser, lo decía Juan XXIII, una Iglesia de los pobres y para los pobres. Los pobres llevan en su ser mismo la presencia del Reino, y es su condición de pobreza la que debe siempre llevarnos de la reflexión a la acción, a la caridad. Entender esto no es fácil ya que implica una honda renovación eclesial y pastoral, aquella que se fue abriendo camino con el Concilio Vaticano II, pero que hoy ha retomado mayor vigencia con el magisterio del papa Francisco.

No ha sido mi intención abordar todos los aspectos del pobre y de su condición de pobreza en la Biblia, eso es imposible. Tampoco he pretendido abrazar estrictamente una mirada desde América Latina, vinculada a la Doctrina Social de la Iglesia, aunque alguna referencia hago. He buscado reflexionar en voz alta, con los textos seleccionados, algunas cuestiones de las condiciones de pobreza y del pobre, y de nuestro compromiso con ellos.

\section{BIBLIOGRAFÍA}

Bovon, F., (2010) Evangelio según Lucas, Salamanca: Sígueme

Córdula L., (2018). Evangelio de Lucas. Hechos de los apóstoles. Navarra: Verbo Divino.

Fernandez, F. (2001). Diccionario de Jesús de Nazaret. Burgos: Monte Carmelo.
García Maestro, J., (2013) El Dios que nos lleva junto a los pobres. La teología de Gustavo Gutiérrez. Salamanca: San Esteban.

Gutiérrez, G., (1974) Teología de la Liberación. Perspectivas. Salamanca: Sígueme.

Gutiérrez, G., (1980) La fuerza histórica de los pobres. Lima: CEP.

Gutiérrez, G., (1995). Hablar de Dios desde el sufrimiento del inocente. Una reflexión sobre el libro de Job. Salamanca: Sígueme.

Gutiérrez, G., (2004) Acordarse de los pobres. Textos esenciales. Lima: Fondo Editorial del Congreso.

Illacuría, I. y Sobrino, J., Mysterium Liberationis. Conceptos fundamentales de la Teología de la Liberación. Madrid: Trotta.

Illacuría, I., (1981) Las Bienaventuranzas como carta fundacional de la Iglesia de los pobres. Madrid: Trotta

Iraburu, J., (1964) Pobreza y pastoral. Navarra: Verbo Divino.

Obras de San Ambrosio I, (1966) Tratado sobre el evangelio de san Lucas, Madrid.

Sicre, J., (1992) Profetismo en Israel. Navarra: Verbo Divino. 